\title{
Faculty Developers \\ as Facilitators of Scholarly
}

Writing

\section{Robert Boice and Jim L. Turner}

California State University, Long Beach

Faculty development programs usually focus on teaching and assume little or no responsibility for facilitating scholarly writing. This detachment from direct intervention clearly does not reflect the importance of writing productivity in the reward structure of academe. Indeed, faculty developers recognize that writing brings a more enduring sense of career satisfaction and personal accomplishment for many faculty than does any other professional activity.

Two general reasons help explain why faculty rarely get formal assistance with writing problems. First is the assumption that adaptive habits of scholarship are something that faculty must acquire on their own. Colleagues who do not write are presumed to be disinterested, lazy, or unfit. The end result of this fitness approach borders on the tragic. Many of the 80 percent of all college and university professors who publish little or nothing report feeling distressed and unfulfilled as professionals (Boice \& Jones, 1984).

A second reason that few faculty developers offer writing programs may be that most of us feel that we lack the necessary credibility and expertise. In fact, little specialized knowledge is required to address common attitudinal and behavioral factors that relate to success in writing and publishing. A number of sources (e.g., Fox, 1985) provide practical suggestions about ways of building collaborative support groups and 
of dealing successfully with editors. Recent work in faculty development shows that academics with little experience in facilitating writing, such as departmental chairpeople, quickly master programs that help increase the scholarly productivity of colleagues (Boice, in press).

Faculty interest in programs designed to facilitate their writing may increase in the near future. Most of the junior faculty currently being hired, even at institutions which have traditionally deemphasized creative scholarship, face increased demands to publish. Further, many of these young faculty are unlikely to find a collegial environment that supports scholarship (Turner \& Boice, 1987).

We encourage developers to confront the fact that writing is often a problematic activity with which faculty need and want help. This paper outlines practical means for implementing the developmental aids listed below. None of the suggested strategies requires any specialized expertise or skills. All have been tried on our own and other campuses with some success.

\section{HOLDING WORKSHOPS ON WRITING} ATTITUDES AND HABITS

An effective initial step in establishing a writing program includes workshops with a structured format for group discussion of common beliefs and practices that may promote writing productivity. We typically limit enrollment to no more than 15 participants because maintaining group membership throughout the series of meetings promotes self-disclosure and involvement.

Our format for workshops begins with a 2-3 page handout (abstracted below) that outlines points for discussion on a given topic. The handouts provide information and prod participants to discuss their own feelings, observations, and experiences.

A value of these workshops derives from the fact that faculty typically view writing as an inherently private activity. Most of us rarely discuss our writing problems or practices with others, particularly our colleagues. The discovery that one's anxieties, procrastination rituals, and other maladaptive behaviors are the norm, rather than some personal aberration, is cathartic. These mutual disclosures clear the air and promote 
the adoption of more constructive attitudes and behaviors. The following abbreviated examples from handouts illustrate workshop topics and content.

WORKSHOP A: Education/demystification about the writing process. This workshop proceeds around discussion of common misbeliefs about writing, for example:

1. "Writing is inherently difficult": In fact, good writing is not much more difficult than collegial conversation. Both writing and conversation carry slight risks of being criticized; but both, when not practiced, carry the potential that faculty will be isolated, unheard, and unstimulated.

2. "Good writing must be original": In fact, little, if any of what we think or write is truly original. Much of what we cherish bears repeating, especially in new perspectives.

3. "Good writing must be perfect": This is no more true for writing than for social conversation. Successful authors realize that perfect manuscripts are unattainable, and that a perfectionistic attitude is counterproductive.

4. "Good writing must be spontaneous; good writers await inspiration before beginning": In fact, writers work best by beginning before they feel fully ready. Writers who await inspiration court writing blocks.

5. "Good writing proceeds quickly": The same writers who procrastinate writing often believe that writing, once under way, should flow effortlessly and that manuscripts should be finished in one or a few marathon sessions.

6. "Good writing is done best in binges. Writing requires large blocks of undisrupted time . . . at least whole mornings, better yet whole days, whole vacations, whole sabbaticals, whole retirements": In fact, writers who write regularly and in brief sessions evidence more productivity and creativity than writers who work in binges (Boice, 1983).

WORKSHOP B: Helping writers get started. This workshop covers ways of generating momentum and ideas for writing. It begins by acquainting participants with a simple technique known as free writing (Elbow, 1973). Participants are asked to move quickly into the task described in the instructions at the top of an otherwise blank sheet:

\section{Generative Writing Sheet I}

Pause just long enough to recall an experience from 
your school years that helped or hindered your writing. Then, before you've had a chance to think it all out, begin writing it spontaneously. Stick to the story, but don't stop for anything. Go quickly without rushing. Don't struggle over form or correctness. Just get something down. Keep it up for 10 minutes.

Faculty often seem a bit surprised by this request, but even the most blocked among them join the group in writing. The experience becomes even more curious as the group proceeds. Everyone writes furiously; most writers write at least a page. This result is a useful demonstration for faculty who believe that writing requires substantial warm-up times and preplanning. When asked to stop, many faculty display reluctance; they dislike stopping once they're on a roll. Their hesitancy to stop helps point out a reason why many faculty write in binges. Writers often fear that they will never again find momentum and/or ideas for writing.

The final surprise comes when writers read their writing aloud. Not only is the quantity remarkable, given the brief investment in time, but so is the quality. When they abandon their self-consciousness, many faculty produce admirably simple, direct, and readable sentences.

WORKSHOP $C$ : Helping writers establish discipline. Establishing momentum and generating useful material turns out to be relatively easy. The more difficult step is getting writers to write regularly, to the point of completing and submitting manuscripts. This workshop consists largely of sharing information about ways to establish a writing regimen; it is organized around an outline of control principles for writing (Boice, 1985b; Hull, 1981).

1. Establish one or a few regular places for writing, places where you do nothing but write. Make writing sites sacred by removing all temptations for not writing.

2. Limit social interruptions during writing sessions by (a) closing your office door, (b) posting a writing schedule, (c) unplugging your phone, and (d) enlisting others to help you observe your schedule.

3. Find another writer to join you for mutually quiet periods of writing, preferably in nondistracting surroundings such as the library. 
4. Make more valued activities (e.g., newspaper reading) contingent on first writing for a minimum period of time. Write while you're fresh (in the morning, if manageable), in brief and regular daily sessions.

5. Plan to work on specific, finishable units of writing in each session. Plan beyond daily goals, scheduling stages of manuscript completion over weeks.

6. Share your writing in its most formative stages, so that constructive critics can have realistic prospects of giving useful feedback.

7. Write in brief, daily sessions regardless of feelings of readiness.

OTHER WORKSHOPS: Arranging workshops around local talent. Once writing programs are under way, the inspiration typically continues to offer other, related workshops. Developers might, for instance, assemble a panel of faculty who publish successfully to provide practical knowledge on ways of coping with editorial systems. Or, present a workshop which reviews published advice on scholarly writing and publishing for faculty (e.g., Fox, 1985; Scarr, 1982).

\section{INSTITUTING WRITER SUPPORT GROUPS}

Writing productivity is enhanced by the appreciation, encouragement, and nurturing of others. Although the lone scholar myth remains prominent in academic lore (Hood, 1985), research suggests that successful scholars are distinguished from their less productive peers by the quality and quantity of their collegial ties (Pelz \& Andrews, 1976).

Although this type of mutual self-help group is highly valued by participants, its occurrence appears surprisingly rare. In one sampling of 100 social science departments, for example, fewer than 25 percent of doctoral programs and fewer than 8 percent of master's level programs had such groups which met at least once a semester. The focus of support groups varies depending on participants, but they generally aim to provide stimulation and reinforcement for writing despite all the competing demands and frustrations (e.g., heavy teaching load, family responsibilities, rejected manuscripts, etc.).

Direct observations and follow-ups of various writer support groups indicate that the qualities of the group most valued by 
its members are not necessarily synonymous with objective criteria of group effectiveness (Boice, in press). Groups rated as most beneficial by faculty included the following components, ranked in order of apparent importance:

1. group generates and shares ideas for writing projects;

2. group meets frequently (at least once a month);

3. group shares practical knowledge about setting reasonable goals for productivity, completing projects, and getting work submitted for publication; and

4. group builds an enduring support network which reinforces values regarding the importance and benefits of scholarly writing.

These faculty self-reports of what satisfied them most, however, did not necessarily result in actual increases in pages written and articles accepted for publication. The factors that did relate more substantially to improved productivity were:

1. group expects each member to bring samples of ongoing writing projects to meetings where they are shared and discussedwith colleagues;

2. group openly discusses the maladaptive ideas and practices of members (e.g., that one can write only in binges);

3. group regularly includes a department chair; and

4. group participation leads to collaborative writing.

An excellent general discussion with practical advice about establishing writing support groups can be found in Hood (1985). She advocates inclusion of actual writing sessions in meetings, recruiting colleagues with whom you will feel comfortable in sharing defeats and triumphs, beginning with goalsetting, assigning someone the role of facilitator, and putting "graduates" of support groups to work as resources.

\section{USING PRODUCTIVE FACULTY TO MODEL IDEAL WRITING HABITS}

Developers can help promote better writing habits by enlisting successful writers to join in regular regimens of writing and discussion of the writing experience with their less successful colleagues. We do this as part of a mentoring program where senior colleagues get rewards for carrying out a structured series of meetings with protegés (i.e., junior faculty). We also ask faculty to volunteer as unpaid mentors/facilitators for 
unproductive colleagues. Few of these requests have been denied.

Role models often provide a compelling demonstration of what extensive testing shows: writing in brief (30-60 minute), daily sessions significantly improves writing productivity over the long run (Boice, 1983). Daily writing increases the number of pages written for already active writers who write in binges. It also helps unproductive faculty who suppose themselves too overscheduled and busy to write.

The basic notion here is simple and straightforward. We believe that writing skills and practices are learned activities, and that exposure to effective models can be a powerful learning strategy. In the immortal words of Lawrence Peter "Yogi" Berra, "You can observe a lot just by watching." The role of the faculty developer here is to create and reinforce opportunities for this form of collegial interaction. One way to arrange such interactions comes in inviting faculty to use a room set aside for writing; our "writing room" at CSU Long Beach encourages productive and unproductive writers to work within sight (and occasional comment) of each other. Here again, faculty in both categories generally respond well to our friendly requests that they participate in such interactions.

\section{MAKING BRIEF, CASUAL VISITS TO FACULTY OFFICES}

Many of us acquire habits that help maintain inactive roles vis-a-vis scholarship. We tend to remain in our offices and wait for problematic faculty to seek us out or to be referred by administrators. This tradition serves to encourage selectivity regarding who interacts with developers and the substantive focus of interaction. It rarely provides naturally occurring opportunities to encourage and assist faculty efforts at scholarly writing.

We urge faculty developers to establish the practice of making brief (10-15 minute), occasional visits to faculty in their offices. These informal visits foster greater trust and improved communication. They also aid in enlisting faculty, especially social isolates or those disinclined to seek help, in developmental activities and goals. When one of those activities is scholarly writing, regular visits by faculty development staff can make a dramatic difference in writing commitment 
and output. The following table (from Boice \& Makosky, 1986) illustrates typical results obtained with and without follow-up contacts.

Long-Term Productivity and Satisfaction of Writing Study Participants

\begin{tabular}{lcccc}
\hline & \multicolumn{4}{c}{$(\mathrm{N}=24)$} \\
& $\begin{array}{l}\text { Writing Productivity } \\
\text { (written pgs. per week) }\end{array}$ & $\begin{array}{c}\text { Self-Satisfaction } \\
(10 \text { points max.) } \\
\text { with writing }\end{array}$ \\
& 1 mon. & 2 yr. & 1 mon. & 2 yr. \\
\hline With field contacts & 10.2 & 7.1 & 7.8 & 7.9 \\
Without field contacts & 6.5 & 1.5 & 7.8 & 6.1 \\
\hline
\end{tabular}

More detailed discussion of how to recruit faculty as voluntary research subjects for such projects is provided elsewhere (Boice, 1986).

\section{HELPING TO ARRANGE MENTORING AND COLLABORATION}

Mentoring and collaboration are important support strategies for helping writers follow through on approaches already discussed. Faculty provided with opportunities to discuss writing problems and ideas with colleagues often discover unforseen opportunities for collaboration. One colleague, for example, may have mounds of unanalyzed data and another the skills and motivation to do the analysis. Someone else may have a surfeit of ideas for publishable papers while another is knowledgeable in the same area but has been unable to focus his or her thoughts and energies on a particular topic.

Developers can play a particularly valuable role in fostering collaboration. Although some faculty will take the initiative and seek each other out, others are apparently reluctant to make the initial contact, even when mutual needs and benefits seem obvious. On our campus we have found several instances where faculty with similar scholarly interests were in different departments and did not know one another. 
In the course of assuming a proactive stance towards scholarship, by leaving his or her office for field visits to faculty at work, the developer gets to know the particular interests and needs of individuals and can offer a sort of intellectual matchmaking service as appropriate occasions arise. Some faculty may need this prodding and encouragement to become more sociable about writing. An informative discussion of the intellectual, emotional, and structural factors involved in the collaborative relationship can be found in a chapter by Fox and Faver (1982). Briefly, they give advice about factors to consider in choosing partners (e.g., matching interests, skills, and primacy of work), in sharing and separating task components, in contracting to keep manuscripts on schedule, and in communicating trust.

\section{BECOMING AN ACTIVE MODEL FOR GOOD WRITING HABITS}

Faculty developers sometimes dismiss the notion that they also can become active scholars. Like many faculty they see themselves as too busy and overscheduled to manage much writing.

Once involved in helping promote the writing of others, however, developers often discover the benefits of practicing what they preach. For a variety of reasons, the process of motivating and instructing faculty leads to constructive selfexamination of one's own writing attitudes and practices.

Those developers who model the system they advocate can significantly enhance their credibility and influence, not only with faculty, but also with other critical groups such as department chairs. Our study of new faculty, for instance, strongly suggests that chairs are a crucial factor in the successful implementation of writing programs. Chairs who actively participated in writing programs and/or who modeled visible levels of scholarship and collegiality were importantly linked to those new faculty who were getting scholarly writing done at rates sufficient for eventual success in retention/tenure/promotion procedures. In contrast, when chairs were uninvolved and claimed to be too busy for scholarship, most of their new young faculty were prone to adopt similar excuses. 


\section{PREPARING FOR RESISTANCE AND FRUSTRATION}

Despite the rewards and success potential for faculty developers who offer the type of program outlined here, such ventures are sometimes difficult. We encourage other developers who undertake such projects to begin with realistic expectations about resistance, frustration, and short-term failure.

The topic of writing, especially of being remiss at getting it done or published, arouses powerful emotions. Defensiveness among faculty is likely to be the norm, not the exception. Resistance toward changing one's approach to writing usually begins by involving "busyness" and then proceeds to a more or less idiosyncratic listing of other reasons or excuses; many comments by faculty reflect deeply held personal convictions that are counterproductive.

With some forewarning, faculty developers can forearm themselves against factors that undermine morale and effectiveness. The list that follows rank-orders (by descending frequency) the most commonly encountered comments of faculty who have participated in our writing workshops:

1. A general negativism towards the value of writing and publishing (e.g., "Ninety percent of what gets published is crap, so why should I add to that pile?").

2. The belief that scholarship and effective teaching are inherently incompatible (e.g., "You can't do both well. Something has to give. Professor $\mathrm{X}$ in my department is a prime example of that.").

3. Assertions that writing is beyond the scope of one's contractual responsibilities (e.g., "When they hired me here, publishing wasn't required. I'm doing what I agreed to do, and that doesn't include writing.").

4. Chronic self-doubts expressed about aptitude for writing and creative scholarship (e.g., "I feel that I have nothing original or significant to say, and am afraid that if I try to publish others will judge me to be an incompetent fraud.").

5. Accounts of personal experience evidently designed to contradict the developer's suggestions about good writing practices. Typically, these begin with a competency display (i.e., "I have published X articles and . . .") before proceeding to the clincher (e.g., "I never begin writing unless I have at least a week of uninterrupted time." Or, "I have found that you have to completely sacrifice your family life." Or, "I never show my 
writing to anyone until it is as perfect as I can make it.").

These and other forms of resistance can, in our experience, be anticipated and dealt with constructively. Many of our own articles about faculty development grew from attempts to answer persistent objections (Boice, 1984; Boice, 1985a; Turner and Boice, 1986). We regularly circulate these manuscripts among developers facing similar arguments from faculty. Usually, faculty reluctance contains elements of truth, and the skilled developer can find nonargumentative ways to explore the various pros and cons of a given comment or criticism.

Facilitators of faculty writing may, inevitably, question whether or not their efforts are worth the time and effort. Some faculty, in our experience, suddenly disappear and avoid any further contact. Some mentoring relationships or collaborations fail. Some workshops draw few attendees. And some support groups wither and disband. In essence, though, presentation of writing programs resembles other faculty development offerings. The developer presents practical ideas in ways that encourage faculty to adopt or modify them as they see fit. Some faculty experience significant and lasting benefits, while others reject most, or all, of what developers offer. When we lead writing programs we remind ourselves that we need to be especially sensitive, understanding, patient, and willing to take risks.

\section{REFERENCES}

Boice, R. (1983). Contingency management in writing and the appearance of creative ideas. Behaviour Research \& Therapy, 21, 537-544.

Boice, R. (1984). Reexamination of traditional emphases in faculty development. Research in Higher Education, 21, 195-209.

Boice, R. (1985a). The neglected third factor in writing: Productivity. College Composition \& Communication, 36, 472-480.

Boice, R. (1985b). Writing without blocking: A scheme for helping professors write productively, painlessly, and successfully. Available from the Center for Faculty Development, California State University, Long Beach, Long Beach, CA 90840.

Boice, R. (1986). Faculty development via field programs for middle-aged, disillusioned faculty. Research in Higher Education, 25, 115-135.

Boice, R. (in press). Chairs as facilitators of scholarly writing. The Department Advisor. 
Boice, R., and Jones, F. (1984). Why academicians don't write. Journal of Higher Education, 55, 567-582.

Boice, R., and Makosky, V. P. (1986). Professional writing: Increasing productivity, decreasing pain. Proceedings of Faculty Evaluation and Development: Lessons Learned, 22, 66-75.

Elbow, P. (1973). Writing without teachers. New York. Oxford University Press.

Fox, M. F. (Ed.). (1985). Scholarly writing and publishing: Issues, problems, and solutions. Boulder, CO: Westview Press.

Fox, M. F., and Faver, C. A. (1982). The process of collaboration in scholarly research. Scholarly Publishing, 13, 327-339.

Hood, J. C. (1985). The lone scholar myth. In M. F. Fox (Ed.), Scholarly writing and publishing (pp. 111-125). Boulder, CO: Westview Press.

Hull, G. A. (1981). Effects of self-management strategies on journal writing by college freshmen. Research in the Teaching of English, 15, 135-148.

Pelz, D. C., and Andrews, F. M. (1976). Scientists in organizations: Productive climates for research and development. Ann Arbor, MI: Institute for Social Research.

Scarr, S. (1982). An editor looks for the perfect manuscript. In D. Loeffler, (Ed.), Understanding the manuscript review process: Increasing the participation of women. Washington, DC: American Psychological Association.

Turner, J. L., and Boice, R. (1986). Coping with resistance to faculty development. In M. Svinicki, J. Kurfiss, and J. Stone (Eds.), To Improve the Academy: Resources for Student, Faculty, and Institutional Development (pp. 26-36). The Professional and Organizational Development Network in Higher Education.

Turner, J. L. and Boice, R. (1987). Starting at the beginning: The concerns and needs of new faculty. This volume. 